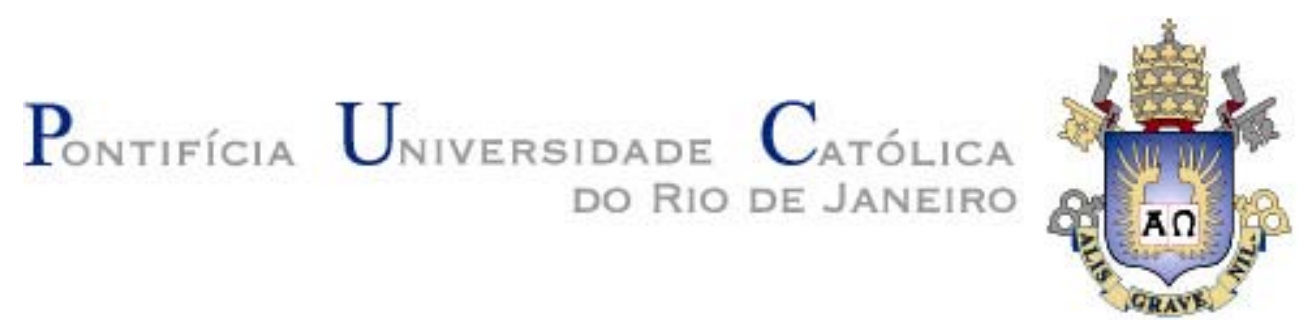

Carolina Monte Ferreira Gonçalves

\title{
As bases lingüísticas para a busca orientada a idéia
}

Dissertação de Mestrado

Dissertação apresentada ao Programa de Pós-graduação em Letras da PUC-Rio como requisito parcial para a obtenção do título de Mestre em Letras.

Orientadora: Violeta de San Tiago Dantas Barbosa Quental

Rio de Janeiro, março de 2006 


\title{
Pontifícia Universidade C atólica \\ DO RIO DE JANEIRO
}

\section{Carolina Monte Ferreira Gonçalves}

\section{As bases lingüísticas para a busca orientada a idéia}

Dissertação apresentada como requisito parcial para a obtenção de grau de Mestre pelo Programa de Pósgraduação em Letras do Departamento de Lestras do Centro de Teologia e Ciências Humanas da PUC-Rio. Aprovada pela Comissão examinadora abaixo assinada.

\author{
Profa. Violeta de San Tiago Dantas Barbosa Quental \\ Orientadora \\ Departamento de Letras - PUC-Rio
}

Profa. Maria Carmelita Padua Dias

Departamento de Letras - PUC-Rio

Profa. Rove Luiza de Oliveira Chishman UNISINOS

Prof. Paulo Fernando Carneiro de Andrade Coordenador Setorial do Centro de Teologia e Ciências Humanas - PUC-Rio

Rio de Janeiro, de de 
Todos os direitos reservados. É proibida a reprodução total ou parcial do trabalho sem autorização da autora, da orientadora e da universidade.

\section{Carolina Monte Ferreira Gonçalves}

Graduou-se em Letras Português Literaturas na Universidade Estadual do Rio de Janeiro em 2003.

Ficha Catalográfica

\section{Gonçalves, Carolina Monte Ferreira}

As bases lingüísticas para a busca orientada a idéia / Carolina Monte Ferreira Gonçalves ; orientador: Violeta de San Tiago Dantas Barbosa Quental. - Rio de Janeiro : PUC, Departamento de Letras, 2006.

132 f. : il. ; $30 \mathrm{~cm}$

Dissertação (mestrado) - Pontifícia Universidade Católica do Rio de Janeiro, Departamento de Letras.

Inclui referências bibliográficas.

1. Letras - Teses. 2. Lingüística computacional. 3. Recuperação de Informação. 4. Teoria sintática. 5. Teoria Semântica. I. Quental, Violeta de San Tiago Dantas Barbosa. II. Pontifícia Universidade Católica do Rio de Janeiro. Departamento de Letras. III. Título. 


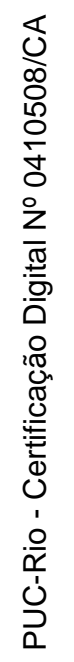

Para Leda 


\section{Agradecimentos}

Ao velho Omolu. Valei-me, meu pai, atotô, Obaluaê.

À minha mãe, Kátia, ao Pedro e ao Rafa, e aos demais familiares - em especial ao Dani pela tradução do resumo.

Ao meu vô Monte (em memória), cuja pequena biblioteca me iniciou nos estudos lingüísticos.

À Ledinha pelo companheirismo, carinho e paciência.

Aos Justas Juliana, Marcelo e ... Edmar pelos projetos megalomaníacos.

Aos amigos Fernando e Carlos pelas conversas e diversões.

À minha orientadora Violeta Quental pelas importantes contribuições.

Aos colegas e professores da Puc-Rio.

Aos funcionários do Departamento de Letras, em especial à sempre prestativa Chiquinha.

Ao CNPq e à Puc-Rio pelos auxílios concedidos. 


\section{Resumo}

Gonçalves, Carolina Monte Ferreira. As bases lingüísticas para a busca orientada a idéia. Rio de Janeiro, 2006. 132p. Dissertação de Mestrado Departamento de Letras, Pontifícia Universidade Católica do Rio de Janeiro.

A busca orientada a idéia é um novo paradigma para mecanismos de busca em acervos compostos por arquivos de texto. Esse paradigma visa resolver um problema comum aos mecanismos de busca: exigir que o usuário preveja as palavras contidas nos documentos que possam conter a informação que procura, impossibilitando-o, assim, de se concentrar diretamente na informação desejada. Buscando solucionar esse problema, são propostas as bases lingüísticas para o desenvolvimento de um modelo teórico preliminar que acrescente dados semânticos aos arquivos de texto. Nesse modelo, a informação semântica de um texto é representada através do que se chamou de estrutura de conceitos. O principal intuito das estruturas de conceitos é representar de uma mesma maneira frases que expressem o mesmo significado, ou seja, as paráfrases apresentam a mesma estrutura de conceitos. Serão expostos nesta dissertação os primeiros elementos do modelo em suas partes semântica, sintática e textual, além da integração entre as mesmas. A dissertação apresenta ainda um estudo de caso a fim de exemplificar o desenvolvimento de uma aplicação para busca de arquivos de texto em que essa tecnologia seria usada.

\section{Palavras-chaves}

Letras; lingüística computacional; recuperação de informação; teoria sintática; teoria semântica. 


\section{Abstract}

Gonçalves, Carolina Monte Ferreira. Linguistic basis for idea-oriented search. Rio de Janeiro, 2006. 132p. Dissertação de Mestrado - Departamento de Letras, Pontifícia Universidade Católica do Rio de Janeiro.

The idea-oriented search is a new pattern for search engines whose databases are composed by text files. This pattern sets out to solve a usual problem for search engines: demanding that users foresee which words are contained in the desired document, keeping them from focusing on the information they are indeed seeking. To solve this problem, the linguistic bases for the development of a theoretical model that can add semantical data to the text files are laid down. In this model, the semantical information of a text is represented by what has been referred to as structure of concepts. The main goal of the structure of concepts is to give one single representation to sentences that express the same meaning. Thus, paraphrases present the same structure of concepts. In this dissertation, the first elements of this model are exposed in its semantical, syntactic and textual parts. Also present are the integration of these elements. A small case study is presented as well, with the intention of illustrating the development of an application for text files databases search engines in which this technology is used.

\section{Keywords}

Computational Linguistics; information retrieval; syntactic theory; semantic theory. 


\section{Sumário}

1 Motivação 12

1.1 A busca orientada a palavra 13

1.2 A busca orientada a idéia $\quad 14$

2 Influências 16

2.1 A gramática de valências 16

2.2 O léxico gerativo 20

2.3 Representações de conceitos 24

2.3.1 Traços semânticos $\quad 24$

2.3.2 Redes semânticas e frames 28

2.4 A web semântica 29

2.5 A UNL e a dependência conceitual 31

2.6 Conclusão do capítulo 34

3 A proposta 35

3.1 Representação semântica 37

3.1.1 O significado do texto como o significado das palavras que o compõem 38

3.1.2 Considerações gramaticais 41

3.1.3 O significado da palavra definido a partir do significado do texto $\quad 47$

3.2 Formalizando a proposta 58

3.2.1 Formalizando as entradas lexicais 62

3.2.2 A estrutura de conceitos das palavras 81

3.2.3 O componente textual do modelo 88

4 Estudo de caso 94

4.1 O dicionário eletrônico 96

4.2 Problemas ainda não resolvidos pelo modelo 117

4.2.3Trabalhos futuros 119

5 Conclusão 121

6 Bibliografia 123

$\begin{array}{ll}7 \text { Anexo - Corpus } & 127\end{array}$ 


\section{Lista de Figuras}

$\begin{array}{ll}\text { Figura } 1 \text { - rede semântica } & 27\end{array}$

Figura 2 - modelo de frames 28

Figura 2 - união dos significados 39

Figura 3 - seqüência dos significados $\quad 40$

Figura 4 - seqüência dos significados em uma paráfrase $\quad 40$

Figura 5 - decompondo um significado 48

Figura 6 - relação argumental $\quad 49$

$\begin{array}{ll}\text { Figura } 7 \text { - significados } & 49\end{array}$

Figura 8 - redistribuindo os significados $\quad 50$

Figura 9 - atribuindo setas iguais às paráfrases 50

Figura 10 - nomes de animais $\quad 51$

Figura 11 - a relação caça 51

Figura 12 - grafo da caça 51

Figura 13 - grafo com outra configuração 52

Figura 14 - novo grafo de caça 52

Figura 15 - grafos congruentes 53

Figura 16 - exemplo de grafos não congruentes 53

Figura 17 - grafo de uma sentença não paráfrase 54

Figura 18 - um grafo contendo outro grafo 56

Figura 19 - subgrafo 56

Figura 20 - habilidades de um grafo $\quad 57$

Figura 21 - grafo de hipônimos contendo o grafo de hiperônimos 58

Figura 22 - algoritmo 1

Figura 23 - algoritmo $2 \quad 59$

Figura 24 - algoritmo $3 \quad 60$

Figura 25 - algoritmo $4 \quad 61$

Figura 26 - algoritmo $5 \quad 62$

Figura 27 - núcleos do sintagma adjetivo e nominal 67 
Figura 28 - ignorando o núcleo do sintagma preposicional 68

Figura 29 - hierarquia entre sintagma nominal do sujeito e sintagma verbal 68

Figura 30 - hierarquia entre sintagma nominal do objeto e sintagma verbal 69

Figura 31 - hierarquia entre os argumentos do verbo 69

Figura 32 - hierarquia entre verbo e seu argumento 69

Figura 33 - hierarquia entre o adjetivo e seu argumento 70

Figura 34 - estrutura do sintagma substantivo 71

Figura 35 - sintagma nominal como argumento do verbo 71

Figura 36 - substituição no sintagma nominal 73

$\begin{array}{ll}\text { Figura } 37 & 73\end{array}$

Figura 38 - estrutura de um sintagma com recursão 73

Figura 39 - recursão no sintagma nominal $\quad 74$

Figura 40 - sintagma preposicionado como argumento do substantivo 75

Figura 41 - recursão no sintagma verbal 75

Figura $42 \quad 75$

Figura 43 - representação da estrutura de argumentos 77

Figura 44 - exemplo de estrutura de argumento $\quad 77$

Figura 45 - seleção semântica 78

Figura 46 - representação da seleção semântica na estrutura de argumentos 78

Figura 47 - exemplo de seleção semântica 78

$\begin{array}{ll}\text { Figura } 48 \text { - grafos congruentes } & 79\end{array}$

Figura 49 - ordenação topológica $\quad 80$

Figura 50 - ordenação topológica na estrutura de argumentos 81

Figura 51 - hiperônimo e hipônimo 84

Figura 52 - exemplo de atribuição de conceitos 86

Figura 53 - representação da estrutura de conceitos 87

Figura 54 - estrutura de argumentos selecionando um grafo 87

Figura 55 - exemplo de grafo conexo 89

Figura 56 - exemplo de grafo desconexo 89

Figura 57 - coordenação 1

Figura 58 - coordenação $2 \quad 91$ 
$\begin{array}{ll}\text { Figura } 59 \text { - anáfora } 1 & 91\end{array}$

Figura 60 - anáfora $2 \quad 92$

$\begin{array}{ll}\text { Figura } 61 & 98\end{array}$

$\begin{array}{ll}\text { Figura } 62 & 98\end{array}$

$\begin{array}{ll}\text { Figura } 63 & 99\end{array}$

$\begin{array}{lr}\text { Figura } 64 & 99\end{array}$

$\begin{array}{ll}\text { Figura } 65 & 101\end{array}$

$\begin{array}{ll}\text { Figura } 66 & 101\end{array}$

$\begin{array}{ll}\text { Tabela } 1 & 101\end{array}$

$\begin{array}{ll}\text { Tabela } 2 & 102\end{array}$

$\begin{array}{ll}\text { Figura } 67 & 103\end{array}$

$\begin{array}{ll}\text { Tabela } 3 & 104\end{array}$

$\begin{array}{ll}\text { Figura } 68 & 106\end{array}$

$\begin{array}{ll}\text { Figura } 69 & 106\end{array}$

$\begin{array}{ll}\text { Figura } 70 & 107\end{array}$

$\begin{array}{ll}\text { Tabela } 4 & 108\end{array}$

$\begin{array}{ll}\text { Figura } 71 & 108\end{array}$

$\begin{array}{ll}\text { Tabela } 5 & 109\end{array}$

Tabela $6 \quad 112$

$\begin{array}{ll}\text { Tabela } 7 & 113\end{array}$

Tabela $8 \quad 114$

$\begin{array}{ll}\text { Tabela } 9 & 116\end{array}$ 